\title{
Measuring Self-Care and Diabetes Distress Among Diabetic Patients
}

\author{
Dwi Prihatiningsih ${ }^{1, *}$ Agustina Rahmawati ${ }^{2}$ \\ ${ }^{1}$ Nursing Department Universitas 'Aisyiyah Yogyakarta, Yogyakarta, Indonesia \\ ${ }^{2}$ Nursing Department Universitas 'Aisyiyah Yogyakarta, Yogyakarta, Indonesia \\ ${ }^{*}$ Corresponding author. Email: dwiprihatiningsih@unisayogya.ac.id
}

\begin{abstract}
Impact of diabetes distress on diabetes self-care practices have been widely investigated but little known about the implication of the diabetes self-care on diabetic distress. This study is a correlational study that aims to discover the prevalence of distress and its correlation with self-care behavior in type II diabetes patients. This research was conducted in January-August 2018. Findings revealed that $70.5 \%$ of respondents had low self-care behavior and $50 \%$ of respondents experienced moderate to high level of distress. Chi-square test showed that there was no association between self-care and distress in type 2 diabetes patients as indicated by the value $\mathrm{p}=0.4>$ of 0.05 . Health care for diabetes patient should focus on both physical and psychological health problems.
\end{abstract}

Keywords: diabetes, self-care, diabetes distress

\section{INTRODUCTION}

Diabetes mellitus (DM) is a global health problem experienced by nearly 500 million people worldwide in 2019 [1]. Diabetes is one of the most affecting chronic diseases for patients physically [2], [3], mentally [4]-[6] and socio-economically [7]-[9]. One of the psychological impacts experienced by DM patients is Diabetes Distress.

Diabetes Distress (DD) describes the emotional burden caused by stress in diabetes self-care as well as the complications that accompany it [10], [11]. Several studies have stated that the incidence of distress in DM sufferers is quite high in the range of $20-50 \%$ [12], [13]. In a study in three community health clinics in Malaysia, distress was found in $19.6 \%$ of diabetics [13]. Meanwhile, in a study in Bangladesh [12], distress was found in almost half $(48.5 \%)$ of the total respondents with diabetes mellitus. Another study in Iran stated that the average research respondents experienced moderate distress [14]. The results of research on DD in Indonesia stated that nearly $20 \%$ of respondents experienced moderate to severe distress [15], [16].

Diabetic patients with distress will have a negative impact on the patient himself, his family, and health care providers involved in diabetes care. Diabetes distress results in decreased quality of life related to health in all domains, namely physical, psychological, social, and environmental [13], [17]. In another study, distress also had an impact on low adherence to treatment [16].

One of the behavioral factors associated with the incidence of distress in diabetes is self-care. Previous study showed that self-care was significantly associated with the occurrence of distress in diabetics [17]. If selfcare is low, there will be an increase in the incidence of distress in diabetes patients, especially in the aspects of diet, medication, and interpersonal [18]. This study aims to describe self-care behavior and the incidence of distress and to determine the relations of self-care and distress in type $2 \mathrm{DM}$ patients.

\section{METHODS}

This study is a correlational study using a crosssectional approach. In this study purposive sampling was used with 44 participants in total. The samples were outpatient and inpatient at 2 hospitals in Yogyakarta, with minimum age of 20 years old. Samples that were excluded were patients with type I diabetes and patients with leg amputations. This research was conducted in January-August 2018.

The questionnaire used to assess self-care was Indonesian version of Summary of Diabetes Self-Care Activities (SDSCA) [19]. The data obtained were grouped into 2 categories based on the mean value as the cut-off point, namely low if the average value was $<3.5$ and high if $\geq 3.5$.

Diabetes Distress Scale (DDS) [10], 2005) which has been translated and validated in Indonesian [20] was used to assess distress in diabetes. The data obtained were grouped into three categories: Little or no distress with a score of $<2$; Moderate distress with the score 2-2.9 and high distress with $\geq 3$ [21]. Chisquare statistical test was used to identify the link of two variables. 
Table 1. Sociodemographic \& Clinical Characteristics of the Participants

\begin{tabular}{|c|c|c|}
\hline Characteristics & Frequency & Percentage \\
\hline \multicolumn{3}{|l|}{ Gender } \\
\hline Male & 17 & 38.6 \\
\hline Female & 27 & 61.4 \\
\hline \multicolumn{3}{|l|}{ School } \\
\hline No School & 1 & 2.3 \\
\hline Primary School & 14 & 31.8 \\
\hline Secondary School & 25 & 56.8 \\
\hline University & 4 & 9.1 \\
\hline \multicolumn{3}{|l|}{ Marital Status } \\
\hline Single/Not married & 2 & 4.5 \\
\hline Married & 37 & 84.1 \\
\hline Widowed & 5 & 11.4 \\
\hline \multicolumn{3}{|l|}{ Employment } \\
\hline Employed & 21 & 47.7 \\
\hline Unemployed/Retired & 23 & 52.3 \\
\hline \multicolumn{3}{|l|}{ Income (million IDR) } \\
\hline$<1$ & 17 & 38.6 \\
\hline $1-3$ & 21 & 47.7 \\
\hline $3-10$ & 6 & 13.6 \\
\hline \multicolumn{3}{|c|}{ Health insurance ownership } \\
\hline Yes & 41 & 93.2 \\
\hline No & 3 & 6.8 \\
\hline \multicolumn{3}{|l|}{ Diabetes duration } \\
\hline$\leq 5$ years & 13 & 30.2 \\
\hline$>5$ years & 30 & 69.8 \\
\hline \multicolumn{3}{|c|}{ Family History of diabetes } \\
\hline No & 19 & 43.2 \\
\hline \multirow[t]{2}{*}{ Yes } & 25 & 56.8 \\
\hline & Mean & Standard Deviation \\
\hline Age (years) & 57,9 & 11.7 \\
\hline
\end{tabular}

\section{RESULT}

The samples in this study were 44 people with a composition of more female $(61.4 \%)$ than male $(38.6 \%)$. More than half of the participants had a secondary school education $(56.8 \%)$ and were married $(84.1 \%)$. The percentage of respondents who were still actively working was slightly lower than those who did not work or retired with the largest income in the range of 1-3 million rupiahs per month $(47.7 \%)$.

Almost all respondents in this study had health insurance (93.2\%). Most of the respondents had long been diagnosed with $\mathrm{DM}>5$ years $(69.8 \%)$ and more than half of the respondents had a history of DM in their families. The mean age of the respondents was $57.9 \pm$ 11.7 years. The detailed sample profile can be seen in Table 1.

Most of the participant had low self-care behavior $(70.5 \%)$ (table 2) with specific diet was the highest adherence, and foot care was the lowest adherence of diabetic self-care (table 2). Among 44 participants, the proportion of diabetes distress was $50 \%(\mathrm{n}=22)$ which included $45.5 \%(n=20)$ moderate distress and $4.5 \%$ $(n=2)$ high distress (table 2). Three of four dimensions of Diabetes Distress Scale were moderate $(<3.0)$ (table $3)$. This study shows that self-care is not one of the factors that affects distress in diabetic patients (table 4). 
Table 2. Self-care Behavior and Diabetes Distress in Diabetes Mellitus Patients

\begin{tabular}{|l|l|l|}
\hline Categories & Frequency & Percentage \\
\hline Self-care & & 70.5 \\
\hline Low & 31 & 29.5 \\
\hline High & 13 & 100 \\
\hline Total & 44 & \\
\hline & & \\
\hline Diabetes Distress & & 50.0 \\
\hline Little or no distress & 22 & 45.5 \\
\hline Moderate distress & 20 & 4.5 \\
\hline High distress & 2 & 100 \\
\hline Total & 44 & \\
\hline
\end{tabular}

Table 3. Mean Score of Self Care and Diabetes Distress Domains

\begin{tabular}{|c|c|}
\hline Categories & Means \\
\hline Self-Care Domain & 4.5 \\
\hline Specific Diet & 4.2 \\
\hline General Diet & 3.1 \\
\hline Exercise & 2.3 \\
\hline Blood-Glucose Testing & 0.5 \\
\hline Foot Care & \\
\hline Diabetes Distress Domain & 2.1 \\
\hline Physical Distress & 2.0 \\
\hline Emotional Burden & 2.0 \\
\hline Interpersonal Distress & 1.8 \\
\hline Regimen Distress & \\
\hline
\end{tabular}

Table 4. Chi-square test result

\begin{tabular}{|c|c|c|c|c|c|c|c|}
\hline \multirow{2}{*}{ Diabetes } & \multicolumn{9}{|c|}{ Diabetes Distress } & $p$ \\
\cline { 2 - 7 } & Little or no distress & Moderate distress & \multicolumn{2}{c|}{ High distress } \\
\cline { 2 - 7 } & $\mathrm{f}$ & $\%$ & $\mathrm{f}$ & $\%$ & $\mathrm{f}$ & $\%$ & 0.4 \\
\hline Low & 20 & 52.6 & 16 & 42.1 & 2 & 5.3 & 0 \\
\hline High & 2 & 33.3 & 4 & 66.7 & 0 & 0 \\
\hline
\end{tabular}

\section{DISCUSSION}

The results showed that $70.5 \%$ of respondents had low self-care behavior. This result was higher than previous research which found as many as $63.8 \%$ of respondents still had low self-care [22]. Self-care in DM patients was an action taken by individuals to control DM disease which included seven ways namely healthy diet, be active, controlling, take the medication, addressing a problem, risk reduction and, positive coping [23]. By running good self-care management, patients had a good implication on glycemic control and also the quality of life in DM patients [24].

Self-care behavior in DM patients could be influenced by several factors, namely treatment, self-efficacy and, situational influences [22]. Two important components in the implementation of DM were namely medicine and diet. The results of this study showed that the average adherence to the diet was 4.5 days while the adherence to taking the drug was 4.3 days. This indicated that respondents still did not adhere to treatment for a full 7 days. 
Self-care behavior assessed in this study included 5 domains namely specific diet, general diet, physical exercise, blood sugar testing and, foot care [19]. The results showed that patients' compliance with all five domains of self-care was still low with an average number of compliant days of just 2.7 days. These results were lower than previous studies showing an average of 3.8 days of compliance [22]. The results of this study also found the highest sequence of self-care behaviors starting to be the lowest: Special diet, general diet, physical exercise, blood sugar testing and, foot care. These results were in line with previous research showing that foot care in DM patients was still low [25]. Foot care behavior was influenced by several factors namely age, education level, diabetes distress, family support, and, knowledge [25].

Diabetes distress (DD) refers to emotional burdens and unique concern, and sometimes it is hidden when a person is dealing with chronic diseases such as diabetes. Diabetes distress was frequent and different from depression [5], [11]. Diabetes Distress describes the emotional burden caused by stress in diabetes self-care as well as the complications that come with it [10], [11]. The emotional burden will have an impact on the patient himself, his family and the health care providers involved in diabetes care. Diabetes distress results in a decrease in healthrelated quality of life in all domains namely physical, psychological, social and environmental relationships [6].

The results showed that $50 \%$ of respondents experienced a low level of distress, $45.5 \%$ experienced moderate distress and only $8.3 \%$ experienced severe distress. Meanwhile, the average total score of diabetes was 2.07 or in the moderate category. These results were in line with previous research that found the average diabetes distress experienced by participants was in the moderate category [16].

Diabetes Distress Scale has 4 domains namely stress related to emotional burden, doctor/health worker, treatment and, interpersonal. The results of the research on these 4 domains can be seen in table 5 . The results of this study showed that all four domains had an average score of \pm 2 . The sequence of distress levels starts from the highest which

is stressed with a doctor/healthcare provider (mean 2.1), emotional burden (mean 2.0), interpersonal $(2,0)$ and, the lowest on regimen distress $(1,8)$.

The first domain of diabetes distress is the domain of emotional burden. The emotional burden describes the stress associated with personal emotions in patients suffering from DM, including fear of possible complications caused by DM. Personal reactions can be in the form of feeling scared, angry, or feeling that diabetes controls life. The results of this study showed the average score on this domain was 2.0 (moderate distress). The results of this study were in line with previous research that found the average score in this domain was 2.3 [16].
The second domain is stress related to doctors/healthcare providers. This domain describes the stress experienced by DM sufferers during interacting with doctors/healthcare providers. The average score on this domain was the highest among the four domains. The results of this study were in line with previous studies that found the average score in this domain was 2.4 [16].

The third domain is the distress associated with treatment. This domain describes the stress felt by patients with DM caused by the need for compliance with the therapy management plan which is distress caused by too many drugs and needles and self-confidence in the ability to perform diabetes treatment. In this domain, the average value was 1.8. This third domain was the domain with the lowest average score compared to the other three domains. The results of this study were different from previous studies that found stress in this domain belongs to a moderate category with an average score of 2.6 [16].

The fourth domain is interpersonal distress that reflects the psychological emotions and feelings felt by patients with DM during interacting with family, friends, or people around them. This is often caused by friends and family who cannot understand the perceived suffering and do not provide support to diabetic patients. The average score generated on this domain was 2.0 (medium category). These results were in line with previous research that also found this domain belonged to a moderate category with a score of 2.1 [16].

The results of the study have shown that self-care was not correlate with diabetes distress. The results of this study were not in line with previous research showing that one of the determinants of distress was self-care behavior. Previous research found that self-care was significantly associated with distress in diabetes. Another study also found that if self-care was low, there would be an increase in the incidence of stress in diabetic patients [18]. This was most likely due to a relatively small number of participants in this study.

\section{CONCLUSION}

In summary, it can be found that diabetes distress becomes a common health problem which frequently coexists with diabetes mellitus. This study found $50 \%$ cases of diabetes distress and low level of self-care behavior among type 2 diabetes mellitus patient. Health care for diabetes patient should focus on both physical and psychological health problems. The focus of education in DM patients can be done to improve self-care behavior, especially in the behavior of measuring blood sugar and foot care

\section{ACKNOWLEDGMENTS}

We thank to Universitas 'Aisyiyah Yogyakarta, PKU Muhammadiyah Yogyakarta Hospital and PKU Muhamamdiyah Bantul Hospital for the support on this project. We are grateful to all the participants of the study 


\section{REFERENCES}

[1] International Diabetes Federation, "IDF Diabetes Atlas," $2019 . \quad$ [Online]. Available: https://www.diabetesatlas.org/upload/resources/material/2 0200302_133351_IDFATLAS9e-final-web.pdf.

[2] S. G. Wannamethee, A. G. Shaper, P. H. Whincup, L. Lennon, and N. Sattar, "Impact of diabetes on cardiovascular disease risk and all-cause mortality in older men: Influence of age at onset, diabetes duration, and established and novel risk factors," Arch. Intern. Med., vol. 171, no. 5, pp. 404-410, 2011, doi 10.1001/archinternmed.2011.2.

[3] I. Feinkohl, J. F. Price, M. W. J. Strachan, and B. M. Frier, "The impact of diabetes on cognitive decline: Potential vascular, metabolic, and psychosocial risk factors," Alzheimer's Res. Ther., vol. 7, no. 1, 2015, doi: 10.1186/s13195-015-0130-5.

[4] A. Pan et al., "Bidirectional association between depression and type 2 diabetes mellitus in women," Arch. Intern. Med., vol. 170, no. 21, pp. 1884-1891, 2010, doi: 10.1001/archinternmed.2010.356.

[5] J. S. Gonzalez, L. Fisher, and W. H. Polonsky, "Depression in diabetes: Have we been missing something important?," Diabetes Care, vol. 34, no. 1, pp. 236-239, 2011, doi: $10.2337 / \mathrm{dc} 10-1970$

[6] B. H. Chew, R. Vos, S. Mohd-Sidik, and G. E. H. M. Rutten, "Diabetes-Related distress, depression and Distress-Depression among adults with type 2 diabetes mellitus in Malaysia," PLoS One, vol. 11, no. 3, pp. 1-16, 2016, doi: 10.1371/journal.pone.0152095.

[7] E. Herquelot, A. Guéguen, S. Bonenfant, and R. DraySpira, "Impact of diabetes on work cessation: Data from the GAZEL cohort study," Diabetes Care, vol. 34, no. 6, pp. 1344-1349, 2011, doi: 10.2337/dc10-2225.

[8] American Diabetes Association, "Diagnosis and classification of diabetes mellitus," Diabetes Care, vol. 36 Suppl 1, pp. S67-74, 2013, doi: 10.2337/dc13-S067.

[9] T. Seuring, O. Archangelidi, and M. Suhrcke, "The Economic Costs of Type 2 Diabetes: A Global Systematic Review," Pharmacoeconomics, vol. 33, no. 8, pp. 811831, 2015, doi: 10.1007/s40273-015-0268-9.

[10] W. H. Polonsky et al., "Assessing Psychosocial Distress in Diabetes," Diabetes Care, vol. 28, no. 3, pp. 626-631, 2005.

[11] F. J. Snoek, M. A. Bremmer, and N. Hermanns, "Constructs of depression and distress in diabetes: Time for an appraisal," Lancet Diabetes Endocrinol., vol. 3, no. 6, pp. 450-460, 2015, doi: 10.1016/S22138587(15)00135-7.

[12] M. Islam, M. Islam, M. Karim, U. Alam, and K. Yesmin, "Predictors of diabetes distress in patients with type 2 diabetes mellitus," Int. J. Res. Med. Sci., vol. 2, no. 2, p. 631, 2014, doi: 10.5455/2320-6012.ijrms20140549.

[13] B. H. Chew, S. Mohd-Sidik, and S. Shariff-Ghazali, "Negative effects of diabetes-related distress on healthrelated quality of life: An evaluation among the adult patients with type 2 diabetes mellitus in three primary healthcare clinics in Malaysia," Health Qual. Life Outcomes, vol. 13, no. 1, 2015, doi: 10.1186/s12955-0150384-4.

[14] A. Tol et al., "Assessment of diabetic distress and disease related factors in patients with type 2 diabetes in Isfahan: A way to tailor an effective intervention planning in Isfahan-Iran," J. Diabetes Metab. Disord., vol. 11, no. 1, 2012, doi: 10.1186/2251-6581-11-20.
[15] A. Mansur, H. Haryani, and C. Effendy, "Hubungan Motivasi Mencari Pengobatan Dengan Distress Emosional Pada Penderita Diabetes Melitus Tipe 2 Di YOGYAKARTA," Jurnal Ilmu Keperawatan, vol. 4, no. 3. pp. 150-153, 2009.

[16] D. A. Perwitasari et al., "Distress Adherence and Quality of Life of Type 2 Diabetes Mellitus Patients in Indonesia," Int. J. Med. Sci. Innov. Res., vol. 3, no. 6, pp. 23-31, 2018, [Online]. Available: http://eprints.uad.ac.id/14479/1/983715413056914155_IJ MSIR.pdf

[17] Z. Jannoo, Y. B. Wah, A. M. Lazim, and M. A. Hassali, "Examining diabetes distress, medication adherence, diabetes self-care activities, diabetes-specific quality of life and health-related quality of life among type 2 diabetes mellitus patients," J. Clin. Transl. Endocrinol., vol. 9, pp. 48-54, 2017, doi: 10.1016/j.jcte.2017.07.003.

[18] S. Rehan and S. Rehan, "Diabetes Self Care and Diabetic Distress in Patients with Type 2 diabetes," Pakistan J. Prof. Psychol., vol. 6, no. 1, 2015, [Online]. Available: http://pu.edu.pk/images/journal/clinicalpsychology/PDF/p aper 5_v6_1_15.pdf.

[19] D. J. Toobert, S. E. Hampson, and R. E.Glasgow, "The Summary of Diabetes Self-Care," Diabetes Care J., vol. 23, no. 7, pp. 943-950, 2000, doi: 10.2337/diacare.23.7.943.

[20] B. Arifin, D. A. Perwitasari, J. At Thobari, Q. Cao, P. F. M. Krabbe, and M. J. Postma, "Translation, Revision, and Validation of the Diabetes Distress Scale for Indonesian Type 2 Diabetic Outpatients with Various Types of Complications," Value Heal. Reg. Issues, vol. 12, pp. 6373, 2017, doi: 10.1016/j.vhri.2017.03.010.

[21] L. Fisher, D. M. Hessler, W. H. Polonsky, and J. Mullan, "When is diabetes distress clinically meaningful? Establishing cut points for the diabetes distress scale," Diabetes Care, vol. 35, no. 2, pp. 259-264, 2012, doi: $10.2337 / \mathrm{dc} 11-1572$.

[22] A. D. Kurnia, A. Amatayakul, and S. Karuncharernpanit, "Predictors of diabetes self-management among type 2 diabetics in Indonesia: Application theory of the health promotion model," Int. J. Nurs. Sci., vol. 4, pp. 260-265, 2017.

[23] Association of Diabetes Care \& Education Specialists, "AADE7 Self-Care Behaviors," 2020. https://www.diabeteseducator.org/living-withdiabetes/aade7-self-care-behaviors.

[24] R. Amelia, "The Model of Self Care Behaviour and the Relationship with Quality Of Life, Metabolic Control and Lipid Control of Type 2 Diabetes Mellitus Patients in Binjai City , Indonesia," Maced. J. Med. Sci., vol. 6, no. 9, pp. 1762-1767, 2018.

[25] Y. Sari et al., "Foot self-care behavior and its predictors in diabetic patients in Indonesia," BMC Res. Notes, vol. 13, no. 1, pp. 4-9, 2020, doi: 10.1186/s13104-020-4903-y. 